\title{
Correction to: X-linked hypophosphatemia and growth
}

\author{
R. Fuente ${ }^{1} \cdot$ H. Gil-Peña ${ }^{2} \cdot$ D. Claramunt-Taberner ${ }^{1} \cdot$ O. Hernández ${ }^{1}$. \\ A. Fernández-Iglesias ${ }^{1}$ - L. Alonso-Durán ${ }^{1}$ - E. Rodríguez-Rubio ${ }^{1}$ - F. Santos ${ }^{1,2}$
}

Published online: 7 November 2017

(C) Springer Science+Business Media, LLC 2017

\section{Correction to: Rev Endocr Metab Disord (2017) 18:107-115 https://doi.org/10.1007/s11154-017-9408-1}

The authors of the article titled as "X-Linked Hypophosphatemia and growth", published in the journal "Reviews in Endocrine and Metabolic Disorders" https://doi.org/10.1007/s11154-017-9408-1, would like to note an error in the acknowledgements section of this paper. The error is on page 112 in the description of financial support. We would like to add the agreement to the Severo Ocha Grant 2013-2017 in the framework of "Programa Estatal de Promoción del Talento y su Empleabilidad en I+D+I, Subprograma Estatal de Formación", which financed the research activity of the main author of the article.
This error has no implications for the analysis or the reported results.

The Agreement section must be:

This work was supported by the National Plan I + D + I 20082011, Instituto de Salud Carlos III (PI12/00987) and also by the National Plan I + D + I 2013-2016 Instituto de Salud Carlos III (PI14/00702 and PI15/02122), European Regional Development Funds 2013-2016 (ERDF, Grupín 14-020), the Foundation of the University of Oviedo (FUO), and by the Severo Ocha Grant 2013-2017 in the framework of "Programa Estatal de Promoción del Talento y su Empleabilidad en I+D+I, Subprograma Estatal de Formación".

The online version of the original article can be found at https://doi.org/ 10.1007/s11154-017-9408-1

\section{F. Santos}

fsantos@uniovi.es

1 Division of Pediatrics, Department of Medicine, Faculty of Medicine, University of Oviedo, Oviedo, Asturias, Spain

2 Department of Pediatrics, Hospital Universitario Central de Asturias (HUCA), Oviedo, Asturias, Spain 